\title{
Engaging the ASEAN Diaspora: Type 2 Diabetes Prevalence, Pathophysiology, and Unique Risk Factors among Filipino Migrants in the United States
}

\author{
Maria Rosario Araneta \\ Department of Family Medicine and Public Health, University of California San Diego, School of Medicine, United States of America
}

\begin{abstract}
Type 2 diabetes prevalence is rising rapidly in Southeast Asia (SEA) where urbanization and adoption of 'western' behavioral lifestyles are attributed as predominant risk factors. The Southeast Asian diaspora to the United States has resulted in a sizable portion of migrant and US born SEAs, with approximately 4 million Filipino Americans, 2 million Vietnamese-Americans, Cambodians $(330,000)$, and Thai $(300,000)$ as the most populous. Their longer exposure to a western lifestyle and participation in clinical studies with other racial/ethnic groups, provide opportunities to evaluate etiologic factors which might inform trends and intervention opportunities among residents of Southeast Asia.

Epidemiologic studies in the US have identified higher T2D prevalence among Filipinos (16.1\%) compared to groups perceived to be at highest risk for T2D, namely Latinos (14.0\%), Black (13.7\%), and Native Americans (13.4\%), while SEAs (including Burmese, Cambodian, Indonesian, Laotian, Malaysian, and Thai, 10.5\%) and Vietnamese (9.9\%) had higher T2D risk compared to Whites (7.7\%), despite their absence of general obesity. Asian-Americans, including SEAs, East and South Asians, collectively have higher rates of undiagnosed T2D compared to other racial/ethnic groups in the US. Almost half (44\%) of Filipinos with newly diagnosed T2D have isolated post-challenge hyperglycemia and will remain undiagnosed if current screening practices remain limited to measures of glycosylated hemoglobin and fasting plasma glucose.

The University of California San Diego Filipino Health Study found excess visceral adipose tissue accumulation, low ratio of muscle to total abdominal mass area, low adiponectin concentration, multiparity ( $\geq 6$ live births), and sleep insufficiency ( $<7$ hours) to be unique T2D risk factors among Filipino-American women, even after adjusting for established T2D risk factors including hypertension and parental history of T2D. Social determinants such as low educational attainment (less than college completion), and sustained social disadvantage during childhood and adulthood were independently associated with T2D risk. Gestational diabetes is a known risk factor for future T2DM among women; Northern California data shows that following Asian Indians, gestational diabetes was highest among Filipina and SEA parturients, who had twice the GDM prevalence as Black, Hispanic, and White women. Identification of novel T2D risk factors among SEAs may guide early diagnosis, inform pathophysiology, and identify unique opportunities for T2D prevention and management.
\end{abstract}

Key words: type 2 diabetes, immigration, adiposity, Southeast Asia

\section{Type 2 Diabetes, a global epidemic}

Type 2 diabetes (T2D) is an urgent, global public health problem, including in Southeast Asia. The International Diabetes Federation reported that in 2015, over half $(56 \%)$ of all people with diabetes were living in the South-East Asia Region or the Western Pacific Region. Further, in the next 15 years, by 2035, T2D prevalence is projected to increase by $92 \%$ in Vietnam, by $85 \%$ in the Philippines, by $73 \%$ in Myanmar, by $72 \%$ in Malaysia, by $65 \%$ in Indonesia, and by $36 \%$ in Thailand, ${ }^{1}$ compared to lower incremental increases in the United States (by 22\%), and in neighboring Taiwan (by 34\%), and Korea (by 36\%), and a projected $7 \%$ decrease in Japan. ${ }^{1}$
T2D prevalence in Malaysia is projected to increase to $12.2 \%$ in 2035 , exceeding the projected prevalence in the United States (11.6\%). ${ }^{1}$ The projected T2D prevalence in 2035 in Thailand (8.3\%), Vietnam (8.2\%), Myanmar $(8.0 \%)$, the Philippines (7.1\%), and Indonesia (6.7\%) will exacerbate the burden on medical, fiscal, personnel, and personal resources. Urgent measures to prevent T2D in Southeast Asia, and specifically to further elucidate the unique pathophysiology of T2D in SEAs can inform strategies to prevent, delay, and manage T2D in the ASEAN region.

The colonial relationship between the United States and selected SEA nations, followed by immigration policies
ISSN 0857-1074 (Print) | eISSN 2308-118x (Online)

Printed in the Philippines

Copyright (C) 2019 by the JAFES

Received: September 18, 2019. Accepted: October 30, 2019.

Published online first: November 9, 2019.

https://doi.org/10.15605/jafes.034.02.02
Corresponding author: Maria Rosario G. Araneta, $\mathrm{PhD}, \mathrm{MPH}$

Professor of Epidemiology

Department of Family Medicine and Public Health

Assistant Dean of Diversity and Community Partnerships

University of California San Diego, School of Medicine

9500 Gilman Drive, MC 0606

La Jolla, California, USA 92093-0606

Tel. No.: +1 858-822-4145

Email: haraneta@ucsd.edu 
for family reunification programs, education, and employment to fill selected labor shortages in the US, has resulted in a sizeable SEA diaspora to the United States. US Census data estimates that there are approximately 4 million Filipino Americans, 2.1 million VietnameseAmericans, 331,733 Cambodian Americans, 319,794 Thai Americans, 309,564 Hmong, 265,138 Lao, 193,056 Burmese, 126,935 Indonesian, and 29,431 Malaysian Americans (www.census.gov). ${ }^{2}$ Their long exposure to a western lifestyle and participation in clinical studies with other racial/ethnic groups, provide opportunities to evaluate etiologic factors which might inform etiology and intervention opportunities among residents of Southeast Asia.

The objective of this review paper is to summarize published research on the prevalence and unique T2D risk factors and diagnostic limitations among Filipinos in the United States, which might influence screening, prevention, and management initiatives in the Philippines and the ASEAN region.

\section{Filipino migration to the United States}

Asian Americans have emerged as the fastest growing racial group in the US, and Asian migrants have surpassed Latinos as the largest group of new immigrants in the United States (US), with Filipinos comprising the $4^{\text {th }}$ largest immigrant group, behind Mexicans, Chinese, and Indians. ${ }^{3}$ Filipino migration to the US began as early as 1587 when states such as California and Louisiana belonged to Spain and Mexico. The earliest permanent settle of Filipinos was established in 1763 in Louisiana. Larger cohorts of Filipino migration to the US occurred in three waves, starting with agricultural workers from 1906 to 1935 in Hawaii and California, followed by a second wave of Filipino migrants who joined the US military during and after World War II. The $3^{\text {rd }}$ wave followed in 1965 through family reunification policies, and recruitment of selected professions, including nurses, physicians, and teachers to address labor shortages in the US. The unique historical, military, commercial, educational, and cultural US-Philippine relationship resulted in 4 million Filipino Americans. Approximately half are immigrants, and $40 \%$ reside in California. Selected cities, including Daly City, California and Honolulu, Hawaii have populations where $>25 \%$ of their residents self-report as Filipino.

\section{DM prevalence among Filipino Americans}

The first recorded measures of diabetes among Filipinos in Hawaii was based on a study among 38,103 gainfully employed residents in Oahu, Hawaii during 1958 to 1959. Diabetes was ascertained by serum glucose levels 2 to 2.5 hours after a meal containing at least 50 grams of carbohydrates Diabetes prevalence was already three times higher among Filipinos (2.0\%), Japanese (2.2\%), and Koreans $(2.0 \%)$ compared to Whites $(0.7 \%) 60$ years ago. ${ }^{4}$

Forty years later, between 1997 and 2000, the North Kohala Study in the big island of Hawaii showed T2D prevalence (by 2 hour oral glucose tolerance test) was significantly higher among Filipinos (19.4\%) compared to Whites $(4.4 \%)$, despite their similar body mass index (mean BMI: Filipino: $26.1 \mathrm{~kg} / \mathrm{m}^{2}$ vs White: $25.5 \mathrm{~kg} / \mathrm{m}^{2}$ ).
Although Native Hawaiians had larger BMI $\left(31.3 \mathrm{~kg} / \mathrm{m}^{2}\right)$ compared to Filipinos $\left(26.1 \mathrm{~kg} / \mathrm{m}^{2}\right)$, T2D prevalence was similar among Native Hawaiians (19.0\%) and Filipinos $(19.4 \%) .^{5}$

Recent data from 18,200 participants of the Hawaii Behavioral Risk Factor Surveillance showed age-adjusted diabetes trends between 2011 and 2015 were highest among Native Hawaiians and other Pacific Islanders (NHOPI), followed by Filipinos compared to Japanese Americans and Whites. However, in 2016, Filipinos surpassed NHOPI as having the highest age adjusted diabetes prevalence $(13.7 \%)$ compared to NHOPI $(12.9 \%)$, Japanese $(9.5 \%)$ and Whites $(5.5 \%)$, although obesity prevalence remained higher among NHOPI (45.6\%) compared to Filipinos $(21.2 \%){ }^{6}$ When stratified by age group, Filipinos had the highest T2D prevalence compared to all other ethnic groups in the following age groups: 55-64 years: 21\%, 65 to 74 years: $31 \%$, and $75+$ years: $29 \%{ }^{6}$

Data from the US NHANES (National Health and Nutrition Examination Survey) shows that Asian Americans (AA) have the highest prevalence of undiagnosed T2D compared to all other ethnic groups, where $51 \%$ of Asian Americans with T2D were undiagnosed. ${ }^{7}$ Further, Asian-Americans had similar T2D prevalence $(20.6 \%)$ compared to Blacks (20.8\%) and Latinos (23.1\%), and significantly higher T2D prevalence compared to Whites $(11,5 \%)$; when Asians were stratified by regional origin, T2D prevalence among South Asians (24.8\%) and Southeast Asians (23.3\%) were highest compared to all other ethnic groups, including compared to East Asians (16.0\%). ${ }^{8}$

In California, among 2.2 million members of a large integrated health care system, including 82,781 Filipino patients, T2D prevalence was highest among Pacific Islanders (18.3\%, Native Hawaiians, Samoans, Guamanians), followed by Filipinos (16.1\%) and South Asians (15.9\% Indian, Pakistani, Bangladeshi), exceeding rates among ethnic groups traditionally perceived to be at highest risk for T2D, including Latinos (14.0\%), Blacks (13.7\%) and Native Americans (13.4\%). ${ }^{9}$ Moreover, the 1,876 Southeast Asians (10.5\%, including Burmese, Cambodian, Indonesian, Laotian, Malaysian, and Thai) and 1,671 Vietnamese Americans (9.9\%) had higher T2D prevalence compared to Whites $(7.3 \%)$ despite the absence of general obesity. ${ }^{9}$ Other Asian subgroups also had higher T2D prevalence compared to Whites, including Japanese Americans (10.3\%), Korean (9.9\%), and Chinese Americans $(8.3 \%){ }^{9}$

\section{The UCSD Filipino health study}

The Rancho Bernardo Study (RBS), a longitudinal study of myriad health outcomes, including T2D, began in 1972, and has been instrumental in informing the natural history of several disease outcomes. In 1995, the RBS enrolled two ethnic comparison cohorts, including African-American and Filipino women. Filipinos were selected because they comprise the second largest ethnic group in San Diego, California, following Mexican-Americans, and because of observations of an excess of Filipino dialysis patients at a nearby teaching hospital for military veterans. The observed excess of retired Filipino veterans of the United States Navy with access to health care, and a history of 
frequent exercise and maintenance of normal body mass index (BMI) as required through their military service, precipitated interest regarding the pathophysiology of T2D in non-obese Filipinos, diabetes sequelae, and underdiagnosed T2D. Enrollment was initially limited to women since our existing grant was interested in ethnic differences in osteoporosis. Filipina women, ages 40 years and older were recruited from community venues to a longitudinal study of osteoporosis, type 2 diabetes, cardiovascular disease and regional obesity. ${ }^{10}$ Recruitment materials emphasized general health and included bone density testing for osteoporosis and other conditions, to reduce self-selection bias for participants with known diabetes. A total of 453 Filipino women participated in the baseline clinic visit between 1995 to 1999, followed by subsequent clinic visits 5 years later in 2001-2002, and 10 years later (in 2006 to 2007). Between 2006 to 2007, selfidentified Filipino husbands $(n=114)$ of female participants were invited to a baseline visit using the same research protocol, clinic and staff. To our knowledge, the UCSD Filipino Health Study is the oldest, longitudinal study of myriad metabolic conditions among Filipinos in the United States. $^{10-31}$

Filipina immigrants in San Diego had almost three times the T2D prevalence (by oral glucose tolerance test, OGTT) compared to Blacks (32\% vs 12\%), despite having significantly smaller waist circumference and BMI. ${ }^{12}$

\section{Obesity trends}

Studies among migrant populations show increased T2D risk with long duration in the US and increased acculturation to a western lifestyle. Our transnational study showed no difference in T2D prevalence, by fasting hyperglycemia, among Filipino migrants in the San Diego $(14.1 \%)$, long term and US-born Filipinos in Hawaii $(14.7 \%)$ compared to residents in the Philippines $(11.8 \%)$ from the same provinces as the San Diego migrants. ${ }^{13}$ The similarities in fasting hyperglycemia was observed despite higher obesity prevalence among US born and longer term immigrant Filipinos in Hawaii (20\% with BMI $>30 \mathrm{~kg} / \mathrm{m}^{2}$ ) compared to Filipino immigrants in San Diego $(9.3 \%$ with obesity), and Philippine residents from the same provinces as the San Diego migrants $(5.2 \%) .{ }^{13}$ Further,
T2D prevalence (by OGTT) did not differ between Filipino immigrants in San Diego (32\%), long term migrants and US born Filipinos in Hawaii (25\%), ${ }^{13}$ and a Philippine cohort in Luzon ( $25 \%$ among adults aged $<50$ years). ${ }^{32}$

Duration of migration in San Diego included recent and long term migrants, ranging from six months to 47 years. Percent life years (PLY) in the US was computed to account for both age at and years since immigration. Unlike other immigrant groups where obesity increases with longer duration in the United States, no differences in BMI, percent body fat (by dual x-ray energy absorptiometry), truncal fat, nor T2D prevalence (by OGTT) were observed among recent immigrants who spent $<16 \%$ PLY compared to long term migrants who spent almost half of their lives $\left(>42.3 \%\right.$ PLY) in the US. ${ }^{33}$

\section{Regional fat distribution}

Visceral, subcutaneous, pericardial, and muscle to total abdominal mass area were measured by electron beam computed tomography among White, Black, and Filipino women in San Diego, California. Filipinas had significantly more pericardial fat and visceral adipose tissue (VAT) compared to Black and White women despite having significantly smaller waist and BMI compared to Blacks. ${ }^{12,21}$ As shown in Figure 1, VAT volume in a Filipina with $\mathrm{BMI}=20 \mathrm{~kg} / \mathrm{m}^{2}$ and waist circumference and waist circumference of 26 inches, was triple that of an overweight Black woman (VAT: 84 vs $25.4 \mathrm{~cm}^{3}$ ). Even when limited to normal weight women, (BMI $<23 \mathrm{~kg} / \mathrm{m}^{2}$ cut point for Asians), Filipinas had significantly more VAT at every level of waist girth and percent body fat compared to normal weight $\left(\mathrm{BMI}<25 \mathrm{~kg} / \mathrm{m}^{2}\right)$ Black and White women. ${ }^{12}$

Figure 2 shows T2D prevalence was significantly higher among Filipinas at every VAT tertile. However, even among women with the least VAT $\left(<46 \mathrm{~cm}^{3}\right)$, T2D prevalence was just $1.7 \%$ among Caucasians, $7.4 \%$ among Blacks but $23 \%$ among Filipinas. ${ }^{12}$ This suggests that excess VAT explains some, but not all of the attributable risk for T2D among Filipinos. Further, CT measures of VAT are neither convenient nor economical. When limited to women with normal waist girth $(<80 \mathrm{cms}$ for Asians and $<88 \mathrm{cms}$ for Black and White women), Filipinas with normal waist
African-American

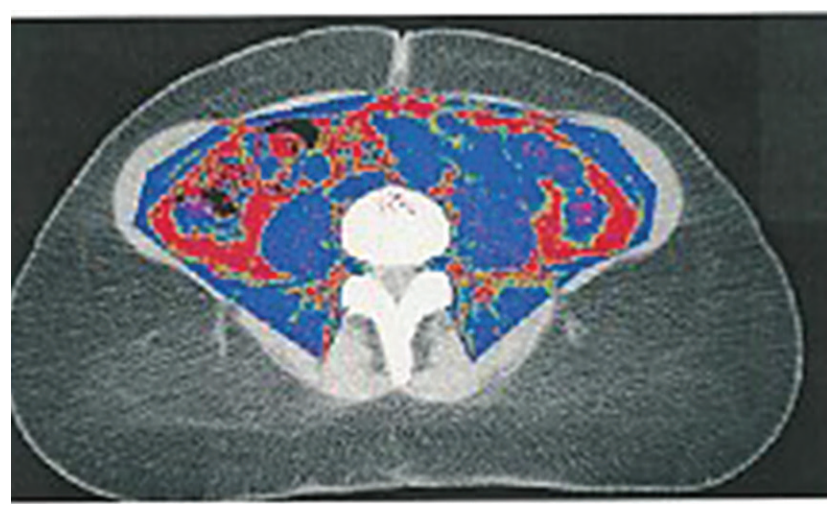

$\mathrm{BMI}=25 \mathrm{~kg} / \mathrm{m}^{2}$, VAT: $25.4 \mathrm{~cm}^{3}$
Filipina

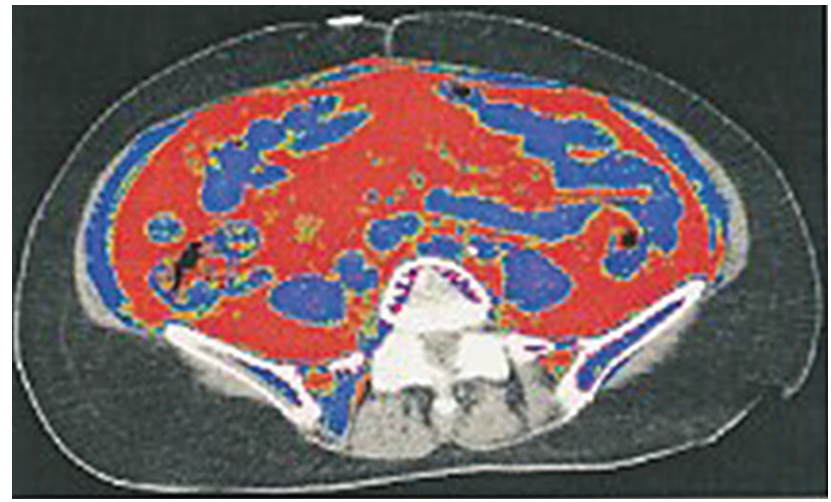

$\mathrm{BMI}=20 \mathrm{~kg} / \mathrm{m}^{2}$, VAT: $84.0 \mathrm{~cm}^{3}$

Figure 1. CT-defined Visceral Adipose Tissue (VAT) African-American vs Filipino-American women. ${ }^{12}$ 


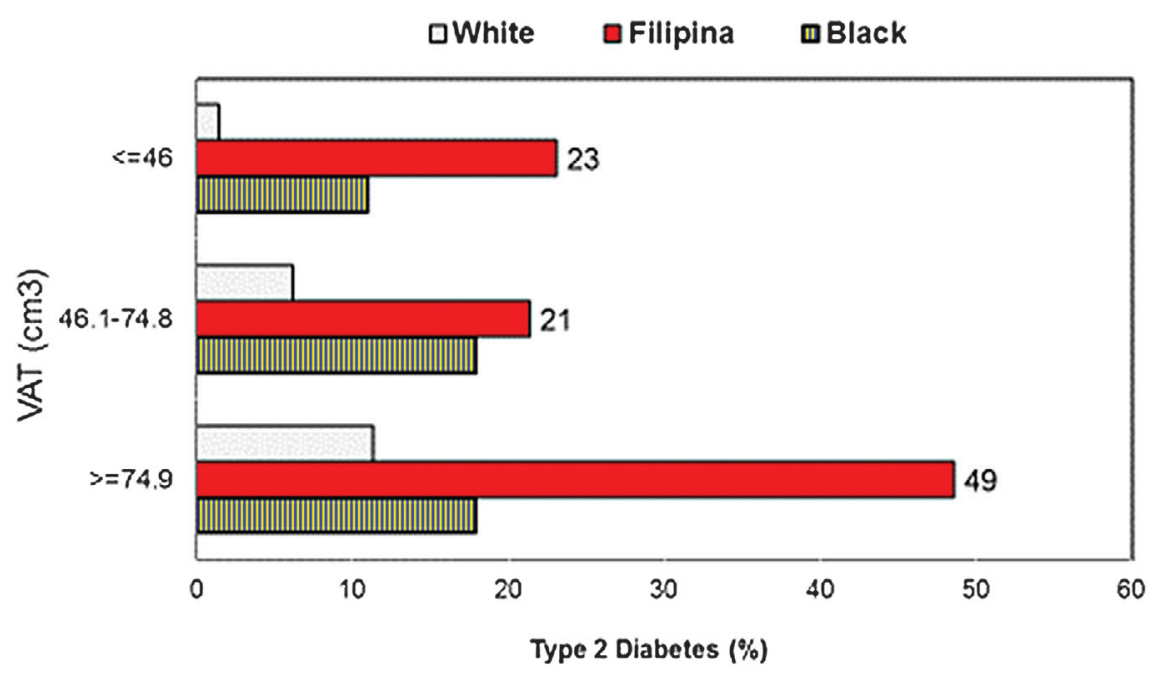

*T2D by OGTT. VAT by computed tomography.

Figure 2. Age-adjusted Type 2 Diabetes* prevalence, by Visceral Adipose Tissue (VAT) tertiles and race, $55-80$ year old women. ${ }^{12}$

girth continued to have significantly more VAT $\left(54.8 \mathrm{~cm}^{3}\right)$ compared to White $\left(50.9 \mathrm{~cm}^{3}\right)$ and Black women $\left(43.8 \mathrm{~cm}^{3}\right)$, and significantly higher T2D prevalence despite normal waist circumference (Filipina T2D: 23.3\%, White, 3.3\%, Black: $10.4 \%){ }^{12}$

Other unique T2D risks among Filipino migrants include low ratio of muscle to total abdominal mass area. Filipinas had significantly more pericardial fat $\left(191 \mathrm{~cm}^{2}\right)$ compared to White $\left(144 \mathrm{~cm}^{2}\right)$ and Black $\left(123 \mathrm{~cm}^{2}\right)$ women, and significantly more percent fat in the rectus abdominus muscle $(35.4 \%)$ compared to White $(24.6 \%)$ and Black women $(26.7 \%) .{ }^{21}$ Neither intermuscular nor intrathoracic far, nor fat in the oblique muscles differed by ethnicity, although White women had significantly more fat in the paraspinal and psoas muscles. ${ }^{21,23}$ In the combined cohort of White, Black and Filipino women in San Diego, postmenopausal women with diabetes had significantly less total abdominal muscle and significantly more visceral adipose tissue than non-diabetics. ${ }^{23,25}$ Increased VAT and decreased muscle mass are independent risk factors for diabetes. In women with BMI $<25 \mathrm{~kg} / \mathrm{m}^{2}$, low muscle to abdominal area was significantly associated with a higher risk for T2D. ${ }^{25}$ Low muscle was associated with normal weight metabolic obesity. Interventions that emphasize increasing muscle, rather than weight loss, could increase glucose storage and consumption, enhancing glucose disposal. Further, increasing muscle mass might improve insulin sensitivity and prevent insulin resistance in low BMI ASEAN populations.

\section{Adiponectin}

Low levels of adiponectin, a cytokine with insulin sensitizing properties, is predictive of T2D; ${ }^{34}$ FilipinaAmericans with normal glucose levels had half the adiponectin concentration of normoglycemic Caucasians. ${ }^{15}$ Mean adiponectin levels among normoglycemic White women were $16 \mathrm{ug} / \mathrm{ml}$ compared to $8 \mathrm{ug} / \mathrm{ml}$ among Filipinas in San Diego, California and $10 \mathrm{ug} / \mathrm{ml}$ in Black Women. Adiponectin levels are down regulated in the presence of excess visceral adipose tissue, ${ }^{34}$ however, these trends persisted even after adjusting for waist, waist-to-hip ratio, BMI, fasting insulin, and insulin resistance (based on homeostatic model assessment, HOMA-IR).

Among Filipinas, T2D prevalence increased with decreasing adiponectin concentration. Among Filpinas with the lowest adiponectin concentration $(<5.4 \mathrm{ug} / \mathrm{ml})$ over half (51\%) had T2D compared to $29 \%$ among those with adiponectin levels ranging from 5.4 to $9.2 \mathrm{ug} / \mathrm{ml}$. Filipinas with the highest adiponectin concentration $\left(\geq 9.3 \mathrm{ug} / \mathrm{ml}\right.$ ) had the lowest T2D prevalence at $17 \%{ }^{35}$

The etiology behind low adiponectin levels among Filipinos might have genetic origins. The Cebu Longitudinal Health and Nutrition Survey conducted a genome wide association study to investigate the genetic loci associated with plasma adiponectin. Among their 1776 unrelated Filipina participants, an uncommon haplotype of rs11924390 (KNG1) and rs864265 (ADIPOQ) was strongly associated with lower adiponectin levels. ${ }^{36}$

\section{Nutrition}

Behavioral factors, specifically, dietary interventions to increase adiponectin concentration have suggested that higher fiber intake can increase adiponectin concentration. A 24-hour food recall questionnaire was administered among the UCSD Filipino Health Study participants, and data were analyzed at the Willett laboratory at Harvard. $^{20}$ Neither intake of protein, carbohydrates, saturated fat, monounsaturated fat nor polyunsaturated fat differed among Filipinas with high versus low adiponectin concentration. ${ }^{20}$

When stratified by OGTT defined diabetes status, neither protein, carbohydrate, nor fat (vegetable, animal, saturated, polyunsaturated, monounsaturated) intake differed among Filipinas with versus without diabetes. Interestingly, Filipinas with T2D had significantly lower calcium intake (736 milligrams) compared to those without diabetes (936 milligrams), and higher caffeine intake (109 vs 61 milligrams). ${ }^{37}$ 


\section{Other metabolic abnormalities}

Other metabolic abnormalities among Filipino migrants include elevated prevalence of the Metabolic Syndrome (MetSyn), hypertension (HTN), dyslipidemia, probable non-alcoholic fatty liver disease (NAFLD, based on hepatic enzymes), hyperuricemia, and inflammation (based on tumor necrosis factor alpha (TNF- $\alpha$ ) levels). ${ }^{10,12,17,22,26}$ For the previous 33 years, HTN prevalence was remained highest among Black and Filipino men and women in California, compared to other ethnic groups. ${ }^{36,37}$ Among Filipino-American women, NAFLD prevalence by hepatic enzymes was similar to that of Hispanic women (17\% and $15 \%$, respectively) and twice that of White and African American women. ${ }^{17}$ Furthermore, NAFLD was independently associated with T2D (adjusted Odds Ratio: 6.3) among Filipinas, after adjusting for visceral adiposity, adiponectin, and other T2D risk factors. ${ }^{17}$

\section{Reproductive risk factors: Gestational diabetes and grand multiparity}

A growing body of evidence indicates that T2D risk begins in-utero, with prenatal exposures, gestational age, low birth weight, and birth complications associated with an increased risk for T2D in adulthood. ${ }^{40}$ Intrauterine exposures including gestational diabetes mellitus (GDM), obesity, maternal stress, poor diet/nutrition, low physical activity, and genetic propensity can lead to childhood metabolic dysregulation, including early onset T2DM. Possible mechanisms include fetal nutrition, altered organ growth and maturation, increased glucocorticoid exposure, and genetic and epigenetic links. ${ }^{40}$

Gestational, childhood, and adulthood genetic, epigenetic and environmental exposures are important and often synergistic determinants of T2D. ${ }^{40}$ Intrauterine growth restriction (IUGR), preterm birth, low-birth weight, chronic undernutrition, and childhood undernutrition followed by overnutrition later in life are associated with adult T2D risk. ${ }^{41-42}$ The 2011 Philippine Food and Nutrition Research Institute (FNRI) survey showed that $16 \%$ of newborns had low birthweight $(<2500 \mathrm{~g})$ and $38 \%$ of infants ages 0-5 months were malnourished. These include $12.4 \%$ who were underweight, and $14 \%$ of infants with stunting, reflecting poor maternal nutrition, while $11.1 \%$ of these babies were wasting, indicative of acute significant food shortage and/or disease. ${ }^{43}$

While the contribution of the fetal environment to T2D susceptibility is well recognized, the mechanisms linking fetal nutrient environment and susceptibility to T2D, are not clear. Adiponectin is an adipocyte and placental secreted protein involved in a variety of metabolic processes including insulin and mTOR signaling sensitivity; ${ }^{44-45}$ changes in adiponectin levels in the developing fetus could affect programming of T2D in adulthood. Adiponectin levels are lower in normoglycemic Filipino compared to Black and White women ${ }^{15}$ and could be explained, in part, by expression of single nucleotide polymorphisms in an uncommon haplotype at KNG1-ADIPOQ. ${ }^{35}$ Sub-optimal levels of maternal and fetal adiponectin could alter placental insulin/mTOR signaling and pancreatic beta-cell function in the offspring. Infants with IUGR show reduced circulating insulin levels and impaired beta cell function, however, adiponectin concentration in Filipino IUGR infants and their mothers is unknown. Mechanisms that explain how maternal and fetal undernutrition influences metabolic abnormalities may provide crucial information on the pathophysiology of T2D in the Philippines, which can guide modifiable interventions to improve clinical outcomes.

Gestational, childhood, and adulthood genetic, epigenetic and environmental exposures are important and often synergistic determinants of T2D. ${ }^{40-41}$ Preterm birth, lowbirth weight, IUGR, chronic undernutrition and childhood undernutrition followed by overnutrition later in life are associated with adult T2D risk. California data from the Northern California Kaiser Permanente Hospitals including 230,000 births, showed Asian Indian and FilipinoAmerican parturients had the highest GDM prevalence in Northern California. Filipina-Americans had significantly higher GDM prevalence (10.9\%) compared to Black, White, and Latina $(4.4 \%$ to $6.8 \%$ ) mothers despite the absence of preconceptional obesity. ${ }^{46}$ Further, GDM risk was higher among Philippine born migrants in California compared to US born Filipinas. ${ }^{46}$ Additionally, low prepregnancy adiponectin concentrations six years prior to pregnancy were associated with a five-fold higher risk of gestational diabetes in this cohort of racially diverse women. ${ }^{47}$

Multiparity has been associated with T2D, primarily through post-partum weight retention. To determine whether multiparity is associated with T2D, independent of visceral adipose tissue (VAT) and adipokines, data from the UCSD Filipina Health Study showed that mean parity was 4.3 (range 1-12 births), and T2D prevalence increased with increasing parity. T2D prevalence was $25 \%$ in the low parity group (1-2 births), $30.3 \%$ in women who had 3 to 5 live births, and was $50 \%$ among women with grand multiparity: 6-12 births. ${ }^{19}$ Family history of diabetes, exercise, insulin resistance, and leptin and ghrelin levels did not differ by parity group. Compared with women who had 1-2 live births, women with 6 or more births were significantly older (62 vs. 57 years), had lower college completion ( 22 vs. $58 \%, p=0.006$ ), more hypertension (72 vs. $55 \%$ ), higher VAT (74.9 vs. $\left.58.4 \mathrm{~cm}^{3}\right)$, and lower adiponectin concentration (5.79 vs. $7.61 \mathrm{mcg} / \mathrm{ml})$. In multivariate analysis adjusting for adiponectin, VAT, family history of diabetes, age, education, hypertension, and estrogen use, grand multiparous women had a threefold higher odds of T2D (adjusted odds ratio 3.40 [95\% CI 1.13-10.2]) compared with low parity women. No differences were observed in the odds of diabetes between women in the medium and low parity groups.

Multiparity is associated with elevated T2D risk among Filipina migrants in the US, ${ }^{19}$ but deciphering the complex etiology of T2D, including in-utero exposures, is essential to curtail the emerging T2D epidemic in cultures where large families are valued, and countries where women have limited contraceptive options.

\section{Lifecourse exposures: War, displacement, and food insecurity}

Lifecourse exposures, beginning with adverse fetal exposures such as maternal malnutrition, preterm birth, and childhood stunting exacerbate T2D risk. Malnutrition 
is pervasive in the Philippines, where two-thirds (69.3\%) are food insecure households, and over one-third (38\%) of infants, ages $0-5$ months were malnourished. ${ }^{43}$ Chronic malnutrition persisted through early childhood, and stunting rates were $41.5 \%$ among 3 -year-old toddlers. ${ }^{43}$ Stunting in toddlers is often irreversible, affecting brain development, physical growth, metabolic function, and increasing their future risk for $\mathrm{T} 2 \mathrm{D}$ and cardiovascular disease (CVD) as adults. ${ }^{48}$

Food shortages and malnutrition were widespread during World War II, including the Netherlands where official rations were as low as $500 \mathrm{kcal}$ per day. ${ }^{49}$ The Dutch Winter Families Study and other cohorts experiencing famine showed that infants who experienced prenatal malnutrition had glucose abnormalities later in life, including impaired glucose tolerance and hyperglycemia. ${ }^{49-52}$ Similarly, during the Japanese occupation of 1941-45, food shortages and malnutrition were ubiquitous in the Philippines, and infant mortality rates were reportedly among the highest in the world. To assess the potential influence of wartime fetal and infant malnutrition (up to age 2), data from the UCSD Filipino Health Study were stratified into birth cohorts: born a) before 1938, b) 2 years prior to the Japanese occupation (1938-40), c) during up to two years after the occupation (1941-1947) or d) more than 2 years post occupation (>1947). Participants born prior to the Japanese occupation were significantly taller than those born during or after World War II, however, T2D risk did not differ by birth cohort. ${ }^{14}$

The impact of war and political instability among warexposed populations in Vietnam, Cambodia, Laos, displaced communities such as the Hmong and Rohingya, refugees and asylum seekers, and communities displaced by political insurgencies or destructive natural disasters require urgent evaluation and intervention.

\section{Poverty: Leg length, childhood and adult socio- economic disadvantage}

Childhood socioeconomic disadvantage influences early growth and adult health in myriad forms, including, but not restricted to poor early diet. Poor growth, particularly of the tibia and fibula in the first years of life, has been associated with insulin resistance and coronary heart disease (CHD) and may contribute to an increased risk of T2D and CHD. Leg length among UCSD Filipino Health Study participants was quantified as the difference between standing and sitting heights, and was used as an estimate of childhood growth and nutrition. Diabetes risk did not differ by leg length, however, coronary heart disease was significantly higher among women with the shortest leg length $(<68.6 \mathrm{~cm})$ compared to women with the longest leg length $(>84.5) .{ }^{14}$

Filipinas reporting poor childhood family income had a mean height of 1.52 meters and were significantly shorter than women who reported being 'well off' during childhood. ${ }^{14}$ Women with sustained childhood and adulthood socioeconomic disadvantage had a fivefold higher odds of T2D in later adulthood compared to those with higher childhood and adulthood incomes. ${ }^{14}$ The odds of diabetes were significantly lower in women with better childhood financial conditions, higher education, and higher adult income in analyses that adjusted for BMI, waist circumference, family history of diabetes, smoking, exercise, employment status and household size.

Poverty, income inequality, poor nutrition, and limited social mobility are urgent and modifiable social determinants that exacerbate T2D risk, which require structural changes to eliminate these disparities.

\section{Behavioral factors: Insufficient sleep}

Sleep deprivation has been associated with obesity, insulin and T2D, so the UCSD Filipino Health Study evaluated ethnic differences in the associations of nighttime sleep and daytime napping durations with type 2 diabetes. Filipinas had the shortest average sleep durations (6.3 hours) compared to White (7.3 hours) and Black women (6.6 hours), and had the longest napping durations (31.7 minutes among Filipinas) compared to 16.8 minutes among Whites, and 25.9 minutes among Black women. ${ }^{28}$ T2D prevalence among those with sleep data was $10.9 \%$ among White women, 37.8\% among Filipinas, and 17.8\% among Black women. Sleep duration showed a significant $(p<0.01)$ nonlinear association with T2D in Filipina women, with increased odds of diabetes at both low ( $<6$ hours) and high ( $>9$ hours) sleep durations independent of age, BMI, triglyceride to high-density lipoprotein (HDL) ratio, hypertension, and daytime napping duration. ${ }^{28}$ Daytime napping duration was associated with type 2 diabetes only among White women. Although approximately one-third of Filipina participants in San Diego were nurses, we did not ask about night shift work, nor the reasons for their shorter sleep duration.

Business Process Outsourcing is a thriving industry in the Philippines, where Filipino call center employees work during the graveyard shift in Manila and Cebu, to accommodate business hours in the United States. Anecdotal data have reported sleep deficiency and increasing obesity prevalence among such workers, and exacerbates their risk for T2D and other metabolic abnormalities.

\section{Future directions}

Public health efforts to reduce obesity and physical inactivity are necessary interventions to curtail the emerging diabetes epidemic in Southeast Asia; however, efforts to further elucidate the unique pathophysiology of T2D in populations with 'metabolically abnormal but normal weight phenotype' are urgently needed. The mechanisms of excess visceral adipose tissue accumulation despite normal BMI and waist circumference among Filipinos and other Asians are poorly understood. Non-invasive methods to diagnose and eliminate such excess VAT among normal weight individuals require development and implementation, including increasing muscle mass.

While over nutrition has manifested into a global epidemic of obesity and T2D, social inequities, including poverty, sustained childhood and adulthood fiscal disadvantage, lower education, food insecurity, and specifically prenatal malnutrition, threatens generations of resource-limited Southeast Asians with a higher risk of both gestational and type 2 diabetes. 
Emerging technology, including genome wide association studies (GWAS) of glycemic traits, obesity, T2D, and other metabolic disorders have allowed identification of T2D susceptibility loci and insights pertaining to pathophysiology. However, the role of these loci among 'metabolically abnormal but normal weight' phenotypes common among Filipinos and other Southeast Asians have not been fully characterized. GWAS studies are in progress in China and Japan to identify such loci, but their environmental and behavioral exposures differ from Asians-Americans, and may differ from Southeast Asians.

Metabolite profiling represents a valuable tool to measure and assess unmeasured environmental factors. Several metabolites have been consistently associated with T2D, including selected branch chain and aromatic amino-acids, and low glutamine-to-glutamate ratio. Moreover, recent work suggests metabolite and genetic risk loci provide complementary and independent information for the T2D prediction. However, the role of these metabolites on disease susceptibility in populations of non-European descent has not been fully interrogated.

Other T2D risk factors include known risk factors including diet, exercise, social disadvantage, and selected comorbidities. Genomic and metabolomics measures are associated with some of these factors and could advance knowledge regarding the intersection of biological and sociocultural risk factors with T2D. Studies need to address these gaps in knowledge of the genetics and biology of diabetes in Southeast Asians, including assessment of genetic variation and profile the metabolome of subjects from ASEAN countries, and the ASEAN diaspora.

\section{References}

1. Guariguata L, Whiting DR, Hambleton I, Beagley J, Linnenkamp U, Shaw JE. Global estimates of diabetes prevalence for 2013 and projections for 2035. Diabetes Res Clin Pract. 2014;103(2):137-49. PMID: 24630390. https://doi.org/10.1016/j.diabres.2013.11.002.

2. United States Census Bureau. 2017 American community survey. 1-year estimates. https://factfinder.census.gov/faces/tableservices/jsf/ pages/productview.xhtml? src=bkmk\#.

3. Pew Research Center. The rise of Asian Americans. April 4, 2013, Washington, DC. http://www.pewsocialtrends.org/2012/06/19/the-riseof-asian-americans/.

4. Sloan NR. Ethnic distribution of diabetes mellitus in Hawaii. JAMA. 1963;183:419-24. PMID: 13989245. https://doi.org/10.1001/ jama.1963.03700060061008.

5. Grandinetti A, Kaholokula JK, Theriault AG, Mor JM, Chang HK, Waslien C. Prevalence of diabetes and glucose intolerance in an ethnically diverse rural community of Hawaii. Ethn Dis. 2007;17(2):2505. PMID: 17682354.

6. Uchima $\mathrm{O}, \mathrm{Wu} \mathrm{YY}$, Browne $\mathrm{C}$, Braun KL. Disparities in diabetes prevalence among native Hawaiians/Other Pacific Islanders and Asians in Hawaii. Prev Chronic Dis. 2019;21:16:E22. PMID: 30789820. PMCID: PMC6395081. https://doi.org/10.5888/pcd16.180187.

7. Menke A, Casagrande S, Geiss L, Cowie CC. Prevalence of and trends in diabetes among adults in the United States, 1988-2012. JAMA. 2015;314(10):1021-9. PMID: 26348752. https://doi.org/10.1001/ jama.2015.10029.

8. Cheng YJ, Kanaya AM, Saydah S, Araneta MR, Kahn HS, Imperatore G. Prevalence of diagnosed and total diabetes among Asian-Americans, 2011-2014. Diabetes. 2017;67(Suppl 1):310. https://doi.org/10.2337/db18310-OR.

9. Karter AJ, Schillinger D, Adams AS, et al. Elevated rates of diabetes in Pacific Islanders and Asian subgroups: The Diabetes Study of Northern California (DISTANCE). Diabetes Care. 2013:36(3):574-2. PMID: 23069837. PMCID: PMC3579366.

10. Araneta MR, Wingard DL, Barrett-Connor E. Type 2 diabetes and metabolic syndrome in Filipina-American Women: A high-risk nonobese population. Diabetes Care. 2002;25(3):494-9. PMID: 11874936.

11. Araneta MR, Barrett-Connor E. Subclinical coronary atherosclerosis in asymptomatic Filipino and white women. Circulation. 2004;110(18):2817-23. PMID: 15505100.
12. Araneta MRG, Barrett-Connor E. Ethnic differences in visceral adipose tissue and type 2 diabetes: Filipino, African-American, and white women. Obes Res. 2005;13(8):1458-65. PMID: 16129729.

13. Araneta MR, Morton DJ, Lantion-Ang L, et al. Hyperglycemia and type 2 diabetes among Filipino women in the Philippines, Hawaii, and San Diego. Diabetes Res Clin Pract. 2006;71(3):306-12. PMID: 16236379. PMCID: PMC1383725. https://doi.org/10.1016/j.diabres.2005.07.012.

14. Langenberg C, Araneta MR, Bergstrom I, Marmot M, Barrett-Connor E. Diabetes and coronary heart disease in Filipino-American women: Role of growth and life-course socioeconomic factors. Diabetes Care. 2007;30(3):535-41. PMID: 17327317. PMCID: PMC2542981. https://doi. org/10.2337/dc06-1403.

15. Araneta MR, Barrett-Connor E. Adiponectin and ghrelin levels and body size in normoglycemic Filipino, African-American and white women. Obesity (Silver Spring). 2007;15(10):2454-62. PMID: 17925471.

16. Magno CP, Araneta MR, Macera CA, Anderson GW. Cardiovascular disease prevalence, associated risk factors, and plasma adiponectin levels among Filipino American women. Ethn Dis. 2008; 18(4):458-63. PMID: 19157250

17. Wong CA, Araneta MR, Barrett-Connor E, Alcaraz J, Castañeda C,Macera C. Probable NAFLD, by ALT levels, and diabetes among Filipino-American Women. Diabetes Res Clin Pract. 2008;79(1):13340. PMID: 17764776. PMCID: PMC4512638. https://doi.org/10.1016/j. diabres.2007.07.012.

18. Araneta MR, Grandinetti A, Chang HK. A1C and diabetes diagnosis among Filipino-Americans, Japanese-Americans, and native Hawaiians. Diabetes Care. 2010:33(12);2626-8. PMID: 20833866. PMCID: PMC2992202. https://doi.org/10.2337/dc10-0958.

19. Araneta MR, Barrett-Connor E. Grand multiparity is associated with type 2 diabetes in Filipino-American women, independent of visceral fat and adiponectin. Diabetes Care. 2010:33(2);385-9. PMID: 19918009. PMCID: PMC2809288. https://doi.org/10.2337/dc09-1477.

20. Medina-Torne S, Araneta MR, Macera CA, Kern M, Ji M. Dietary factors associated with adiponectin in Filipino-American women. Ethn Dis. 2011;21(2):190-5. PMID: 21749023.

21. Wassel CL, Laughlin GA, Araneta MR, et al. Associations of pericardial and intrathoracic fat with coronary calcium presence and progression in a multiethnic study. Obesity 2013;21(8):1704-12. PMID: 23666866 PMCID: PMC3748173. https://doi.org/10.1002/oby.20111.

22. Calvo RY, Araneta MR, Kritz-Silverstein D, Laughlin GA, BarrettConnor E. Relation of serum uric acid to severity and progression of coronary artery calcium in postmenopausal White and Filipino women (from the Rancho Bernardo study). Am J Cardiol. 2014;113(7);1153-8. PMID: 24513465. https://doi.org/10.1016/j.amjcard.2013.12.022.

23. Larsen BA, Allison MA, Kang E, et al. Associations of physical activity and sedentary behavior with regional fat deposition. Med Sci Sports Exerc. 2014;46(3):520-8. PMID: 23924920. PMCID: PMC3916942. https:// doi.org/10.1249/MSS.0b013e3182a77220.

24. Armenta RF, Kritz-Silverstein D, Wingard D, et al. Association of breastfeeding with postmenopausal visceral adiposity among three racial/ ethnic groups. Obesity (Silver Spring). 2015;23(2):475-80. PMID: 25522135. PMCID: PMC4310786. https://doi.org/10.1002/oby.20956.

25. Larsen BA, Allison MA, Laughlin GA, et al. The association between abdominal muscle and type ii diabetes across weight categories in diverse post-menopausal women. J Clin Endocrinol Metab. 2015; 100(1):E105-9. PMID: 25250636. PMCID: PMC4283010. https://doi. org/10.1210/jc.2014-2839.

26. Djibo DA, Araneta MR, Kritz-Silverstein D, Barrett-Connor E, Wooten W. Body adiposity index as a risk factor for the metabolic syndrome in postmenopausal Caucasian, African American, and Filipina Women. Diabetes Metab Res 2015; 9(2):108-13. PMID: 25470644. PMCID: PMC4256139. https://doi.org/10.1016/j.dsx.2014.04.011.

27. Araneta MRG, Kanaya AM, Hsu WC, et al. Optimum BMI cut-points to screen Asian-Americans for type 2 diabetes. Diabetes Care. 2015; 38(5):814-20. PMID: 25665815. PMCID: PMC4407753. https://doi.org/ 10.2337/dc14-2071.

28. Shadyab AH, Kritz-Silverstein D, Laughlin GA, Wooten WJ, BarrettConnor E, Araneta MR. Ethnic-specific associations of sleep duration and daytime napping with prevalent type 2 diabetes in postmenopausal women. Sleep Med. 2015;16(2):243-9. PMID: 25637103. https://doi.org/10.1016/j.sleep.2014.11.010.

29. Wassel CL, Laughlin GA, Saad SD, et al. Associations of abdominal muscle area with 4-year change in coronary artery calcium differ by ethnicity among post-menopausal women. Ethn Dis. 2015:25(4):435 42. PMID: 26673520. PMCID: PMC4671440. https://doi.org/10.18865/ ed.25.4.435.

30. Nguyen BJ, Mac N, Faigl A, Araneta M. 390 Utility of video education for expansion of updated Asian American Diabetes screening guidelines. J Invest Med. 2018;66(1):A229. https://doi.org/ 10.1136/jim2017-000663.390

31. Hsu WC, Araneta MR, Kanaya AM, Chiang JL, Fujimoto W. BMI cut points to identify at risk Asian Americans for type 2 diabetes screening. Diabetes Care. 2015:38(1):150-8. PMID: 25538311. PMCID: PMC4392932. https://doi.org/10.2337/dc14-2391. 
32. Baltazar JC, Ancheta CA, Aban IB, Fernando RE, Baquilod MM. Prevalence and correlates of diabetes mellitus and impaired glucose tolerance among adults in Luzon, Philippines. Diabetes Res Clin Pract 2004;64(2):107-15. PMID: 15063603. https://doi.org/10.1016/j. diabres.2003.10.013.

33. Araneta MRG, Wingard DL, Barrett-Connor E. Proportion of life years in the US is not associated with obesity or fat distribution in Filipina immigrants. American Public Health Association, 131st Annual Meeting. San Francisco, CA, November 15-19, 2003.

34. Chandran M, Philips SA, Ciaraldi T, Henry RR. Adiponectin: More than just a fat cell hormone. Diabetes Care. 2003;26(8):2442-50. PMID 12882876. https://doi.org/10.2337/diacare.26.8.2442.

35. Araneta MR, Barrett-Connor E. Ethnic differences in adiponectin, leptin and ghrelin levels in normal glucose tolerant Filipino, Caucasian and African-American Women. American Diabetes Association. 65th Annual Meeting and Scientific Sessions. San Diego, CA, June 10-14, 2005. Diabetes. 2005;54:A262

36. Wu Y, Li Y, Lange EM, et al. Genome-wide association study for adiponectin levels in Filipino women identifies $\mathrm{CDH} 13$ and a novel uncommon haplotype at KNG1-ADIPOQ. Hum Mol Genet. 2010;19(24):4955-64. PMID: 20876611. PMCID: PMC2989895. https:// doi.org/10.1093/hmg/ddq423.

37. Medina S and Araneta MRG. Nutrition and Risk for Type 2 Diabetes Among Filipino Women. San Diego Epidemiology Research Exchange. La Jolla, CA, May 14, 2004

38. Stavig GR, Igra A, Leonard AR. Hypertension among Asians and Pacific Islanders in California. Am J Epidemiol 1984;119(5):677-91. PMID: 6720667. https://doi.org/10.1093/oxfordjournals.aje.a113789.

39. Zhao B, Jose PO, Pu J, et al. Racial/ethnic differences in hypertension prevalence, treatment, and control for outpatients in northern California, 2010-2012. Am J Hypertens. 2015;28(5):631-9. PMID: 25352230. PMCID: PMC4462650. https://doi.org/10.1093/ajh/hpu189.

40. de Boo HA, Harding JE. The developmental origins of adult disease (Barker) hypothesis. Aust N Z J Obstet Gynaecol. 2006;46(1):4-14. PMID: 16441686. https://doi.org/10.1111/j.1479-828X.2006.00506.x

41. Franks PW, Hanson RL, Knowler WC, et al. Childhood predictors of young-onset type 2 diabetes. Diabetes. 2007:56(12):2964-72. PMID: 17720898. PMCID: PMC6419722. https://doi.org/10.2337/db06-1639.

42. Dulloo AG, Jacquet J, Seydoux J, Montani JP. The thrifty 'catch-up fat' phenotype: Its impact on insulin sensitivity during growth trajectories to obesity and metabolic syndrome. Int J Obes (Lond). 2006:30(Suppl 4):S23-35. PMID: 17133232. https://doi.org/10.1038/sj.ijo.0803516.
43. Philippine Nutrition Facts and Figures 2011. Food and Nutrition Research Institute, Department of Science and Technology. Manila, Philippines December 2012. http://122.53.86.125/facts_figures2011.pdf. Accessed on February 13, 2016.

44. Alejandro EU, Gregg B, Wallen $\mathrm{T}$, et al. Maternal diet-induced microRNAs and mTOR underlie $\beta$ cell dysfunction in offspring. J Clin Investig. 2014:124(10):4395-410. PMID: 25180600. PMCID: PMC4191023. https://doi.org/10.1172/JCI74237.

45. Jansson T, Aye I, Goberdhan DC. The emerging role of mTORC1 signaling in placental nutrient-sensing. Placent.a 2012:33(Suppl 2):e239. PMID: 22687819. PMCID: PMC3463762. https://doi.org/10.1016/ placenta.2012.05.010

46. Hedderson M, Ehrlich S, Sridhar S, Darbinian J, Moore S, Ferrara A Racial/ethnic disparities in the prevalence of gestational diabetes mellitus by BMI. Diabetes Care. 2012:35(7):1492-8. PMID: 22619080. PMCID: PMC3379591. https://doi.org/10.2337/dc11-2267.

47. Hedderson MM, Darbinian J, Havel PJ, et al. Low prepregnancy adiponectin concentrations are associated with a marked increase in risk for development of gestational diabetes mellitus. Diabetes Care. 2013:36(12):3930-7. PMID: 23990523. PMCID: PMC3836148. https://doi. org/10.2337/dc13-0389.

48. Caulfield LE, Richard SA, Rivera JA,et al, Stunting, wasting and micronutrient deficiency disorders. In Jamison DT, Breman JG, Meacham AR, et al, eds. Disease control priorities in developing countries. 2nd edition. Washington DC: World Bank; 2006. Chapter 28.

49. Lumey LH, Stein AD, Kahn HS, et al. Cohort profile: The Dutch Hunger Winter families study. Int J Epidemiol. 2007:36(6):1196-1204. PMID 17591638. https://doi.org/10.1093/ije/dym126.

50. Roseboom TJ, Painter RC, van Abeelen AF, Veenendaal MV, de Rooij SR. Hungry in the womb: What are the consequences? Lessons from the Dutch famine. Maturitas 2011:70(2):141-5. PMID: 21802226. https://doi. org/10.1016/j.maturitas.2011.06.017.

51. Li Y, He Y, Qi L, et al. Exposure to the Chinese famine in early life and the risk of hyperglycemia and type 2 diabetes in adulthood. Diabetes. 2010:59(10):2400-6. PMID: 20622161. PMCID: PMC3279550. https://doi org/10.2337/db10-0385.

52. Ravelli AC, van der Meulen JH, Michels RP, et al. Glucose tolerance in adults after prenatal exposure to famine. Lancet. 1998:351(9097):173-7. PMID: 9449872. https://doi.org/10.1016/s0140-6736(97)07244-9.

Authors are required to accomplish, sign and submit scanned copies of the JAFES Author Form consisting of: (1) Authorship Certification, that authors contributed substantially to the work, that the manuscript has been read and approved by all authors, and that the requirements for authorship have been met by each author; (2) the Author Declaration, that the article represents original material that is not being considered for publication or has not been published or accepted for publication elsewhere, that the article does not infringe or violate any copyrights or intellectual property rights, and that no references have been made to predatory/ suspected predatory journals; (3) the Author Contribution Disclosure, which lists the specific contributions of authors; and (4) the Author Publishing Agreement which retains author copyright, grants publishing and distribution rights to JAFES, and allows JAFES to apply and enforce an Attribution-Non-Commercial Creative Commons user license. Authors are also required to accomplish, sign, and submit the signed ICMJE form for Disclosure of Potential Conflicts of Interest. For original articles, authors are required to submit a scanned copy of the Ethics Review Approval of their research as well as registration in trial registries as appropriate. For manuscripts reporting data from studies involving animals, authors are required to submit a scanned copy of the Institutional Animal Care and Use Committee approval. For Case Reports or Series, and Images in Endocrinology, consent forms, are required for the publication of information about patients; otherwise, appropriate ethical clearance has been obtained from the institutional review board. Articles and any other material published in the JAFES represent the work of the author(s) and should not be construed to reflect the opinions of the Editors or the Publisher.

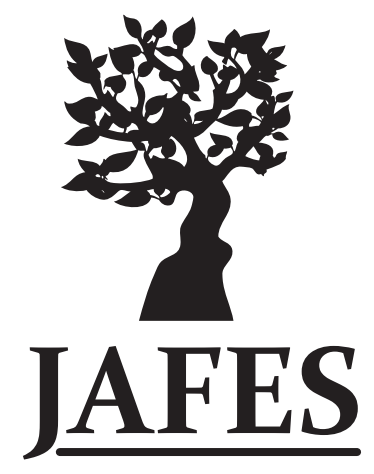

\section{Experience the new JAFES. \\ Visit us at www.ASEAN-endocrinejournal.org.}

